\title{
Developing Peer-to-Peer Accommodation in Macao
}

\author{
Ting Liu ${ }^{1, \text { a }}$, Wei Ding ${ }^{1}$ \\ ${ }^{1} \mathrm{PhD}$ Candidates \\ Faculty of International Tourism and management \\ City University of Macao \\ Choi Kai Yan Building, Avenida Padre Tomas Pereira, Taipa, Macau \\ aE-mail: tingliu86@163.com
}

Key Words: sharing economy, peer-to-peer accommodation, laws and regulations

Abstract. Home stay, bed-and-breakfast, couch surfing are not new things, but peer-to-peer market exploded in recent years, because of economic consideration and technology development, making online payments convenient. As a dynamic tourist city, Macao's peering market is not so active due to lack of official recognition. Therefore, this paper tends to discuss the possibility and feasibility of developing peer-to-peer accommodation in Macao.

\section{Introduction}

Airbnb has started from the USA in 2008 and defined itself as "a trusted community marketplace for people to list, discover, and book unique accommodations around the world---online or from a mobile phone”(Airbnb). Despite its widespread coverage and fast development, Airbnb's way of operation is not acknowledged in Macao. In July 2010, the Macao government passed the No. 3/2010 Law - Proibição de Prestação Ilegal de Alojamento, prohibitions about providing accommodation to the public without a license or in non-hotel buildings or units. Under this context, the online hosts registered in Airbnb are mostly lending the rooms illegally.

It is undeniable that the No. 3/2010 Law did helped to organize and standardize the market, and solve some social safety problems. However as a popular tourist destination, Macao's "attempts to ban the phenomenon mean a disincentive to innovation and protect oligopolistic markets" (Oskam, J. and A. Boswijk 2016). Therefore, this paper intends to discuss the possibility and feasibility for Macao to develop/legalize peer-to-peer accommodation like Airbnb. It will be organized as follows. First, the concept of sharing economy is introduced. Second, possibility and feasibility is discussed with proper statistics. Third, conclusion is given based on the previous discussions.

\section{Sharing Economy}

In 2011, Time Magazine named collaborative consumption/sharing economy, which entails renting, lending, and sharing of goods, as one of "10 ideas that will change the world" using the headline “Today's smart choice: Don’t own. Share” (Walsh, 2011). Over the last few years, with the widespread applications, sharing economy has gradually infiltrated in people's daily lives. Rideshares like Uber or Didi, short-term rentals like Airbnb, all of these provide platforms for people to share the resources they have. The emerging of sharing economy is considered related to the ecological concerns and financial crisis which shifted people's attitude towards consumption (Hamari, J., M. Sjöklint, et al. 2015). Social, economical and technological developments have made the sharing economy---the peer-to-peer-based activity of obtaining, giving, or sharing the access to goods and services, coordinated through community-based online services (Belk, 2010) ---an appealing alternative for consumers. Albinsson, P. A. and B. Yasanthi Perera (2012) categorized sharing economy into three aspects: sharing product service systems, redistribution 
markets and sharing of lifestyles, each aspect can cause major social impacts.

Besides its social impacts, sharing economy is also a technological phenomenon because of the growth of social media technologies. Social media create a peer-to-peer market place with low entry costs for sellers, improve the matching process for fragmented buyers and sellers to communicate directly, and "implement flexible or auction-based pricing” for buyers through applications, plus the progress of online payment also contributes to its boom(Einav, L., C. Farronato, et al. 2015). Under this sharing context, peer-to-peer accommodation appeals to uses for its low-cost and convenience.

\section{Possibility and Feasibility about Developing Peer-to-Peer Accommodation in Macao}

Despite the No. 3/2010 Law which did not approve the way of operating peer-to-peer accommodation in Macao, it is still possible to find registered hosts in Macao on Airbnb. It's been six years since the law has established, the fast developing technology and economy raised questions about opening the market for peer-to-peer accommodation to stimulate tourism and relating industry in Macao.

\subsection{Current Situation of Macao Tourism}

According to Macao Statistics and Census Service (DSEC) report published on 31 March 2016, there were 106 hotels/ guesthouses operating at the end of February 2016. The number of guest rooms is 32,000, increased $13.9 \%$ year-on-year, with 20,000 5-star hotel rooms and 8,000 4-star hotel room, taking up $87.5 \%$ of the totaled. The average occupancy rate of the first two months is $77.5 \%$, down by $2.5 \%$ comparing last year, and the average length of stay of tourists is 1.4 nights, down by 0.1 night of last year. (DSEC, 2016)

From the statistics given above, it is easily get the conclusion that current hotels/ guesthouses in Macao are sufficient to tourists who stay the night. However it should also be noted that $87.5 \%$ are luxuriant hotel rooms, which is an uneven and unhealthy development for hotel industry. Plus the average length of stay and average occupancy both dropped comparing to the same time last year, hinting a tendency to consider lower end market in hotel industry. If the authority wants to prolong visitors' stay in Macao for more than 1.4 nights, current capability of hotel industry might not be sufficient to handle, as occupancy rate is already high up to $77.5 \%$. The growth of tourism needs more rooms for tourists.

\subsection{Impacts of Peer-to-Peer Accommodation}

Peer-to-peer accommodation is considered a new business mode offering alternatives to tourists. The utilization of it definitely has some impacts in relevant aspects.

For tourists, the use of peer-to-peer accommodation increases their frequency of traveling and expands their destination a choice, tourists tends to lengthen their stay and participate in more activities (Tussyadiah, I. P. and J. Pesonen 2015, Tussyadiah, I. P. 2016).

For traditional hotel industry, the emergence of peer-to-peer accommodation, which provide tourists diversity and local flavor, spurs hotels to innovate (Trivett, V. and S. Staff, 2013, Oskam, J. and A. Boswijk, 2016). Inviting benign competition is good for the industry to sustain in the long term. Although peer-to-peer accommodation may challenge the hotel industry, many user of the platform 
choose it mainly for cost-saving. Hence its impact towards high-end hotels with stable customer resources is limited (Choi, K. H., J. H. Jung, et al. 2015), but lower-end hotels' revenue is directly affected by peer-to-peer accommodation's price advantages (Zervas, G., D. Proserpio, et al. 2015).

For local residents, renting spare rooms can bring extra income to the owner, but converting non-hotel buildings or units into profit-gaining accommodations might bring security issues and increase housing prices in the area (Lee, D. 2016).

It is evident to see that Peer-to-peer accommodation has both negative and positive impacts in some respects; therefore, it is necessary for authorities to regulate it.

\subsection{Examples}

Legal issue has always been the major concern. Both the public and private sectors are facing questions like taxation, licensing, management and supervision etc. Airbnb operates in hundreds of countries, territories, and cities; it may not be practical for Airbnb's terms and conditions to cover all, so informing users of the potentially applicable laws in each jurisdiction where its hosts offer accommodations is important (Kaplan, R. A. and M. L. Nadler 2015). Since Taiwan share similar cultural and geographical background, its practice can be used as a reference for Macao.

On December 12 2001Taiwan Tourism Bureau, Ministry of Transportation and Communications (MOTC) issued Regulations for the Management of Home Stay Facilities, defining the peer-to-peer accommodation as "a lodging facility run as a family sideline business, using the spare rooms of a self-used residence to provide tourists with a rural living experience. Such lodging facilities usually incorporate local culture, natural landscape, ecological environment, environmental resources, and agricultural, forestry, fishery, or livestock farming activities.” The regulations also include articles stating application, licensing, and change of registration, and management and supervision of home stay facilities. Different cities also enacted supplementary regulations based on their own situation.

Besides Taiwan, Japan, UK, France and Germany also has laws and regulations to guide the market. Sharing economy present a new form of business operation, which help to push forward the establishment of new laws to cope with today's fast pace.

Currently, there are no laws and regulations in Macao to give guidance to peer-to-peer accommodation, but from the examples discussed above, the Macao government could consult to Taiwan's Regulations for the Management of Home Stay Facilities, taking a trial in Taipa and Coloane. There are many star-ranking hotels in Taipa, hence introducing cost-saving peer-to-peer accommodation can lengthen tourists' stay, plus the beautiful urban space with charming Portuguese and Chinese buildings, tourists can experience Macao's marriage of the East and West. Coloane is a relatively rural area comparing to the historic center of Macao and Taipa. But it maintains the original fishing village style of Macao, fits for peer-to-peer accommodation because of lack of hotels in the area (Kan, M 2014), and tourists can embrace the tranquility of village life and enjoy local delicacies found in this old neighborhood.

\section{Conclusion}

The rising of peer-to-peer accommodation changes tourists' travel patterns drastically. Based on the 
DSEC's latest report, there is a slight decrease in average hotel occupancy and tourists' length of stay, while the usage of peer-to-peer accommodation leads to longer stay and more active interaction during the visit. Hence it is an inevitable trend for Macao to take experimental approaches in acknowledging and legalizing peer-to-peer accommodation, instead of letting it "grow in the shadow of the law" or purely depend on the sharing platform's self-regulated terms (Dostmohammad, S. and J. Long 2015). Comparing to popular historic center of Macao, Taipa and Coloane is suitable to develop peer-to-peer accommodation in Macao. However this essay is just a preliminary study, there are many other questions the authors haven't brought into discussion, future studies should propose comprehensive evidence on relating aspects.

\section{Reference:}

[1] Airbnb. https://www.airbnb.com/about/about-us. (accessed April 11,2016)

[2] Albinsson, P. A. and B. Yasanthi Perera (2012). "Alternative marketplaces in the 21st century: Building community through sharing events." Journal of consumer Behaviour 11(4): 303-315.

[3] Belk, R. (2010). "Sharing." Journal of consumer research 36(5): 715-734.

[4] Choi, K. H., J. H. Jung, et al. (2015). "The Relationship between Airbnb and the Hotel Revenue: In the Case of Korea." Indian Journal of Science and Technology 8(26).

[5] Dostmohammad, S. and J. Long (2015). "REGULATING THE SHARING ECONOMY."

[6] Einav, L., C. Farronato, et al. (2015). Peer-to-peer Markets, National Bureau of Economic Research.

[7] Hamari, J., M. Sjöklint, et al. (2015). "The sharing economy: Why people participate in collaborative consumption." Journal of the Association for Information Science and Technology.

[8] Heinrichs, H. (2013). "Sharing economy: a potential new pathway to sustainability." GAIA-Ecological Perspectives for Science and Society 22(4): 228-231.

[9] Kan, Man-neng 2014. Research on the Feasibility of Macao’s Minshuku Development from the successful cases. Available at http://www.cdt.gov.mo /article_ view.php?id=25 (accessed April 11,2016)

[10] Kaplan, R. A. and M. L. Nadler (2015). "Airbnb: A Case Study in Occupancy Regulation and Taxation." U. Chi. L. Rev. Dialogue 82: 103.

[11] Lee, D. (2016). "How Airbnb Short-Term Rentals Exacerbate Los Angeles's Affordable Housing Crisis: Analysis and Policy Recommendations." Harv. L. \& Pol'y Rev. 10: 229-255.

[12] Macao Printing Bureau. http://bo.io.gov.mo/bo/i/2010/31/lei03_cn.asp. (accessed April 11,2016)

[13] Macao Statistics and Census Service (DSEC). Package Tours and Hotel Occupancy Rate for February 2016. Available http://www.dsec.gov.mo/Statistic/TourismAndServices/PackageToursAndHotelOccupancy Rate. (accessed April 11, 2016)

[14] Oskam, J. and A. Boswijk (2016). "Airbnb: the future of networked hospitality businesses." Journal of Tourism Futures 2(1): 22-42.

[15] Tourism Bureau, MOTC,Taiwan, Regulations for the Management of Home Stay Facilities. Available at http://admin.taiwan.net.tw/law/law_d_en.aspx?no=9 \&d=39 (accessed April 11, 2016) 
[16] Trivett, V. and S. Staff (2013). What the sharing economy means to the future of travel, Skift.

[17] Tussyadiah, I. P. (2016). "Factors of satisfaction and intention to use peer-to-peer accommodation." International Journal of Hospitality Management 55: 70-80.

[18] Tussyadiah, I. P. and J. Pesonen (2015). "Impacts of Peer-to-Peer Accommodation Use on Travel Patterns." Journal of Travel Research.

[19] Walsh B. 2011. Today's smart choice: Don't own. Share. March 17, 2011. Available at www.time.com/time/specials/packages/article/0,28804,2059521 _2059717_2059710,00.html (accessed April 11, 2016)

[20] Zervas, G., D. Proserpio, et al. (2015). "The rise of the sharing economy: Estimating the impact of Airbnb on the hotel industry." Boston U. School of Management Research Paper(2013-16). 